Article

\title{
Thermal Decomposition and Ceramifying Process of Ceramifiable Silicone Rubber Composite with Hydrated Zinc Borate
}

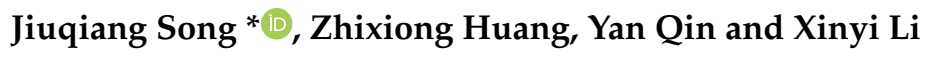 \\ School of Materials Science and Engineering, Wuhan University of Technology, Wuhan 430070, China; \\ duaojianghai@whut.edu.cn (Z.H.); yysjqspeaking@126.com (Y.Q.); 232046@whut.edu.cn (X.L.) \\ * Correspondence: songjq9@126.com; Tel.: +86-159-2727-6450
}

Received: 31 March 2019; Accepted: 13 May 2019; Published: 15 May 2019

\begin{abstract}
The ceramifiable silicone rubber composite was prepared using hydrated zinc borate and kaolin as ceramifiable fillers. Effects of the hydrated zinc borate content and the combustion temperature on the properties of the ceramifiable silicone rubber composite were investigated. Thermal decomposition and ceramifying processes of the composite in a muffle furnace under air were also studied. The results showed that the density and the hardness of the composites increased as the content of the hydrated zinc borate increased from 0 to $30 \mathrm{phr}$. The tensile strength and elongation at break decreased. In addition, hydrated zinc borate decreased the decomposition temperature of the composite, whereas the residue weight under air atmosphere was increased. In the process of decomposition and oxidation of the ceramifiable silicone rubber composite in air, $\mathrm{B}_{2} \mathrm{O}_{3}$ was generated by the decomposition of zinc borate and participated in the formation of the residue network structure, which decreased the temperature of the ceramifying transition. The new phases, zinc aluminate $\left(\mathrm{ZnO} \cdot \mathrm{Al}_{2} \mathrm{O}_{3}\right)$ and aluminum-rich mullite $\left(9 \mathrm{Al}_{2} \mathrm{O}_{3} \cdot 2 \mathrm{SiO}_{2}\right)$, appeared after high-temperature thermochemical reactions. Microscopy images revealed that different structures were formed at different temperatures. The network structure of the ceramic residue became increasingly compact, and the compressive strength increased from 0.31 to $1.82 \mathrm{MPa}$ with the increase of temperature from 800 to $1400{ }^{\circ} \mathrm{C}$, which had a better protective effect on heat transfer and mass loss. The weight loss and the linear shrinkage of the ceramic residue was $37.6 \%$ and $21.9 \%$, respectively, with the $30 \mathrm{phr}$ content of hydrated zinc borate. The bending strength was improved from 0.11 to $11.58 \mathrm{MPa}$, and the compressive strength also increased from 0.03 to $1.14 \mathrm{MPa}$.
\end{abstract}

Keywords: silicone rubber; hydrated zinc borate; thermal decomposition; ceramization

\section{Introduction}

Heat-shielding materials play an important role in the aerospace industry. When space vehicles, rockets, and missiles are flying at high speed, the surface temperature will rise sharply because of severe aerodynamic heating. Meanwhile, heat will be rapidly transferred into the interior structure at ultrahigh temperatures, resulting in damage to inner components. Hence, it is very important for heat-shielding materials to guarantee the normal operation of hypersonic vehicles [1]. In addition, heat-shielding materials can also achieve greater security and ensure public safety under fire [2-4]. Because the traditional polymer materials being used as cable, during a fire, the traditional polymer materials that are being used as cables would be decomposed and release toxic gas, exposing the copper wire and, overall, have a very poor fire-retardant effect. However, ceramifiable polymer composites can overcome this shortcoming. The ceramifiable polymer composites were first proposed by Hanu and his colleagues, and commercialized application was successfully achieved in 2004 [5]. The ceramifiable 
polymer composites, like common polymers, have excellent performance at room temperature and can form hard ceramic shells in fires and at temperature above $600^{\circ} \mathrm{C}$. In recent years, ceramifiable silicone rubber composites have developed rapidly. Ceramifiable silicone rubber composites have relatively lower heat-release rates and minimal sensitivity to external heat flux in comparison to most organic polymer composites $[3,6,7]$. Thermal decomposition of silicone rubber has been thoroughly studied, and good thermal resistance properties have also been demonstrated [8-10]. Ceramifiable fire-resistant silicone rubber composites have been studied by incorporating inorganic fillers, dispersant agent, and other additives into silicone rubber matrix [11]. Eutectic reactions take place at high temperature between mineral fillers and combustion products of silicone rubber, and then the hard, durable ceramic layer with porous structure is formed [12].

Ceramifiable silicone rubber composites are composed of silicone rubber, inorganic fillers, fibers, fluxing agents, and other functional additives, and have the same excellent properties as ordinary silicone rubber. Compared with traditional organic polymers, there are no toxic substances produced during the combustion, and the decomposition product, namely $\mathrm{SiO}_{2}$, can improve the flame-retardant effect [13]. There are also many studies regarding the effects of silicate mineral fillers on silicone rubber ceramization. Zhang [14,15] studied the effects of graphene nanoplatelets, montmorillonite, and silicon carbide whiskers on the properties of ceramifiable silicone rubber composites. A considerable improvement in the mechanical properties and thermal stability of the composites was obtained after surface modification of graphene nanoplatelets. A coordination effect of montmorillonite and silicon carbide whiskers caused the linear and mass ablation rates to decrease by $22.5 \%$ and $18.2 \%$, respectively. The mechanism of ceramifying reaction has also been preliminarily studied. Cheng et al. [16-18] performed numerous studies on ceramifiable mica/silicone rubber, frit-mica/silicone rubber, and other silicone rubber composites. They found that the temperature would be above $800{ }^{\circ} \mathrm{C}$ if the ceramifying reactions were accomplished by eutectic reactions between mica and combustion products of organosilicon. However, the addition of frits could reduce the temperature of ceramifying reactions. Hanu et al. [5] found the ultimate strength of the resultant ceramic residue improved after combustion in air. They confirmed that the eutectic reaction and solidification process was influenced by the particle-size and chemical composition of the fillers, which resulted in the strength improvement of the ceramic residue. In addition, some fluxing agents with low softening temperature, such as glass frits, zinc borate, and zinc or borate oxide, were also introduced into silicone rubber to lower the ceramifying reaction temperature and improve the strength of the ceramic residue. Guo et al. [19] studied the effects of glass frits on the properties, microstructure, and formation mechanism of polysiloxane elastomer-based ceramizable composites, obtaining the optimum contents of the glass frit and catalytic decomposition mechanism of silicone rubber. Anyszka et al. [20] added borate oxide $\left(\mathrm{B}_{2} \mathrm{O}_{3}\right)$ into silicone rubber composites to improve ceramifying reaction at low temperatures, although the thermal stability of the silicone rubber decreased significantly.

Many researchers have focused their attention on the properties of ceramifiable silicone rubber composite with low softening temperature fluxing agents, while ignoring the decomposition and ceramization mechanism of composites at different temperatures. Thus, in this paper, phase transition and reaction mechanism in the process of decomposition and ceramization were discussed. The effect of hydrated zinc borate, acting as fluxing agent, on the ceramifying properties of silicone rubber composite was also investigated.

\section{Experimental}

\subsection{Materials}

Commercial methyl vinyl silicone rubber (SR) was produced by Chengdu Zhonghao Chenguang Technology Co. Ltd. (Chengdu, China). The average molecular weight was 600,000-700,000. The vinyl content of the silicone rubber was $0.13 \%-0.18 \%$ per mole. Fumed silica $\left(\mathrm{SiO}_{2}\right)$ with a Brunauer-Emmett-Teller (BET) surface area of $300 \mathrm{~m}^{2} / \mathrm{g}$ was used to improve the mechanical 
performance of the composites. Hydrated zinc borate $\left(2 \mathrm{ZnO} \cdot 3 \mathrm{~B}_{2} \mathrm{O}_{3} \cdot 3.5 \mathrm{H}_{2} \mathrm{O}, \mathrm{ZB}\right)$ with an average particle size of $5 \mu \mathrm{m}$ was used as fluxing agent, lowering the ceramifying reaction temperature. The hydrated zinc borate released crystal water during $320-450{ }^{\circ} \mathrm{C}$, and the content of crystal water was about $14 \%$ according to thermogravimetric analysis. Kaolin $\left(\mathrm{Al}_{2} \mathrm{O}_{3} \cdot 2 \mathrm{SiO}_{2}\right)$ with an average particle size of $11 \mu \mathrm{m}$ was used as ceramifiable filler. Fumed silica, hydrated zinc borate, and kaolin were purchased from Shanghai Jingchun Bio-Chem Technology Co. Ltd. (Shanghai, China). 2,5-Dimethyl-2,5-di(tert-butylperoxy)hexane (DBPH) was also from Shanghai Jingchun Bio-Chem Technology Co. Ltd., China, and used as the curing agent.

\subsection{Preparation of the Ceramifiable Silicone Rubber Composites}

The ingredients were mixed on a two-roll mill with a gear ratio of 1:1.2 at room temperature. The silicone rubber was first softened, and then fumed silica, kaolin, and hydrated zinc borate were added until a homogeneous batch was obtained. Finally, the curing agent DBPH was added and processed until a visually good dispersion was achieved. The total mixing time was about $30 \mathrm{~min}$. The samples were molded to platens by press vulcanizer at $170{ }^{\circ} \mathrm{C}$ with pressure of $10 \mathrm{MPa}$ for $15 \mathrm{~min}$. Then, the platens were put into an oven at $200^{\circ} \mathrm{C}$ to air-dry for $2 \mathrm{~h}$ for additional vulcanization. The formulations of silicon rubber composites are given in Table 1.

Table 1. Chemical compositions (wt \%) of the ceramifiable silicone rubber composites.

\begin{tabular}{cccccc}
\hline \multirow{2}{*}{ Sample } & \multicolumn{5}{c}{ Ingredients in phr $\mathbf{1}^{\mathbf{c}}$} \\
\cline { 2 - 6 } & SR & SiO $_{\mathbf{2}}$ & Kaolin & ZB & DBPH \\
\hline SR0 & 100 & 40 & 40 & 0 & 2 \\
SR1 & 100 & 40 & 40 & 10 & 2 \\
SR2 & 100 & 40 & 40 & 15 & 2 \\
SR3 & 100 & 40 & 40 & 20 & 2 \\
SR4 & 100 & 40 & 40 & 25 & 2 \\
SR5 & 100 & 40 & 40 & 30 & 2 \\
\hline \multicolumn{7}{c}{}
\end{tabular}

\subsection{Sample Combustion}

Heat-shielding materials or cable prepared with ceramifiable silicon rubber composites are usually used in oxidation environments. Therefore, the combustion of samples $(100 \mathrm{~mm} \times 10 \mathrm{~mm} \times 2 \mathrm{~mm})$ was performed in a muffle furnace under air. In order to obtain the combustion residue at different temperatures, samples were heated from room temperature to 400, 500, 600, 700, 800, 900, 1000, 1100, and $1200{ }^{\circ} \mathrm{C}$ at a heating rate of $10^{\circ} \mathrm{C} / \mathrm{min}$, and kept at each temperature for $30 \mathrm{~min}$, and then cooled to room temperature in the muffle furnace.

\subsection{Characterization}

\subsubsection{Density and Shore A hardness}

The density of the ceramifiable silicone rubber composites with different contents of hydrated zinc borate was measured according to Chinese Standard GB/T 533-2008 at room temperature. Firstly, the density bottle was weighed both before and after placing the sample inside. Then, the density bottle was filled with deionized water and weighed. Before weighing, the bubbles in the bottle and the water on the outer surface of the bottle needed to be removed. After that, the water and sample in the bottle were poured out. Finally, the bottle was filled with deionized water without sample and weighed again. Density was calculated using Equation (1). The reported results were the average value of five specimens.

$$
\rho=\rho_{\mathrm{w}} \frac{\mathrm{m}_{2}-\mathrm{m}_{1}}{\mathrm{~m}_{4}-\mathrm{m}_{3}+\mathrm{m}_{2}-\mathrm{m}_{1}}
$$


where $\rho, \rho_{\mathrm{W}}$ are the density of the sample and the deionized water $\left(\mathrm{g} / \mathrm{cm}^{3}\right)$, respectively. $\mathrm{m}_{1}$ is the mass of the density bottle. $\mathrm{m}_{2}$ is the total mass of the sample and the bottle. $\mathrm{m}_{3}$ is the total mass of the sample, the deionized water, and the bottle. $\mathrm{m}_{4}$ is the total mass of the deionized water and the bottle.

The shore A hardness of the composites with different contents of hydrated zinc borate was conducted by LX-A shore hardness tester (Shanghai Jingmi Instruments Co., Ltd., Shanghai, China) at room temperature. The specimens were $6 \mathrm{~mm}$ thick, and the results were also the average value of five specimens.

\subsubsection{Tensile Strength and Elongation at Break}

The tensile strength and elongation at break tests of the ceramifiable silicone rubber composites with different content of hydrated zinc borate were performed using a universal testing machine (Instron-4465, Instron Engineering Corporation, Norwood, MA, USA) according to Chinese standard GB/T 528-2009. The loading speed was $500 \mathrm{~mm} / \mathrm{min}$. The dimensions of the dumbbell samples were $115 \mathrm{~mm}$ (length) $\times 6 \mathrm{~mm}$ (width of narrow area) $\times 2 \mathrm{~mm}$ (thickness).

\subsubsection{Thermogravimetric Analysis}

Thermal gravimetric analysis (TGA, STA449C/3/G, NETZSCH, Selb, Germany) was conducted to investigate the thermal stability of the samples with different contents of hydrated zinc borate under air. Then, a series of samples were heated at a rate of $10{ }^{\circ} \mathrm{C} / \mathrm{min}$. The relative mass loss and decomposition temperatures of the samples were recorded from room temperature to $1300^{\circ} \mathrm{C}$.

\subsubsection{Fourier Transform Infrared Spectroscopy}

Fourier transform infrared spectroscopy (FTIR) was obtained in the range of $400-4000 \mathrm{~cm}^{-1}$ at a resolution of $1 \mathrm{~cm}^{-1}$ on a Nexus FTIR spectrophotometer (Thermo Nicolet, Waltham, MA, USA) using the $\mathrm{KBr}$ pellet technique for samples after being heat-treated from room temperature to $1200^{\circ} \mathrm{C}$.

\subsubsection{X-ray Diffraction Analysis}

The crystal phases of the ceramic residue were identified by an X-ray diffraction (XRD) with a D8 ADVANCE diffractometer (Bruker, Billerica, MA, USA) with $\mathrm{Cu} K \alpha(\lambda=0.1542 \mathrm{~nm})$ radiation at a generator voltage of $40 \mathrm{kV}$ and a generator current of $400 \mathrm{~mA}$. The scan was conducted from a $2 \theta$ angle of 5 to $80^{\circ}$ with a step interval of $4^{\circ}$.

\subsubsection{Morphology}

The morphology of the ceramic residue after combustion at different temperatures was characterized by field emission scanning electron microscopy (FESEM, Zeiss Ultra Plus, Carl Zeiss NTS GmbH, Oberkochen, Germany).

\subsubsection{Weight Loss and Linear Shrinkage}

The ceramic residue was obtained by heating samples up to $1000{ }^{\circ} \mathrm{C}$ for $30 \mathrm{~min}$ in a muffle furnace under air. The dimensions of the samples were $100 \mathrm{~mm} \times 10 \mathrm{~mm} \times 2 \mathrm{~mm}$. Weight loss of the ceramic residue was evaluated according to Equation (2). Linear shrinkage of the ceramic residue was calculated according to Equation (3).

$$
\begin{gathered}
\mathrm{W}=\frac{\mathrm{M}_{1}-\mathrm{M}_{2}}{\mathrm{M}_{1}} \times 100 \%, \\
\mathrm{~L}=\frac{\mathrm{L}_{1}-\mathrm{L}_{2}}{\mathrm{~L}_{1}} \times 100 \%,
\end{gathered}
$$


where $\mathrm{W}, \mathrm{L}$ are the weight loss and linear shrinkage (\%), respectively. $\mathrm{M}_{1}$ and $\mathrm{M}_{2}$ are the mass of the samples before and after heat treatment, respectively. $\mathrm{L}_{1}$ and $\mathrm{L}_{2}$ are the length of the samples before and after heat treatment, respectively.

\subsubsection{Bending and Compressive Strength}

Bending and compressive strength of the ceramic residue were assessed using a universal testing machine (Instron-4465, Instron Engineering Corporation, Norwood, MA, USA). The loading speed was $2 \mathrm{~mm} / \mathrm{min}$. The compression length was $25 \%$ of the original thickness of the sample. The bending strength and compressive strength were calculated as follows:

$$
\begin{gathered}
\sigma_{\mathrm{f}}=\frac{3 \mathrm{p} \cdot 1}{2 \mathrm{~b} \cdot \mathrm{h}^{2}}, \\
\sigma=\frac{4 \mathrm{~F}}{\pi \mathrm{D}^{2}},
\end{gathered}
$$

where $\sigma_{\mathrm{f}}$ is the bending strength (MPa). $\mathrm{p}$ is the load $(\mathrm{N}) .1, \mathrm{~b}$, and $\mathrm{h}$ are the span length $(\mathrm{mm})$, width $(\mathrm{mm})$, and thickness $(\mathrm{mm})$ of the ceramic residue, respectively. $\sigma, \mathrm{F}$, and D are the compressive strength $(\mathrm{MPa})$, load $(\mathrm{N})$, and specimen diameter $(\mathrm{mm})$, respectively.

\section{Results and Discussion}

\subsection{Density and Hardness of Ceramifiable Silicone Rubber Composites}

Density and shore A hardness of ceramifiable silicone rubber composites with different contents of hydrated zinc borate are shown in Figure 1. The density of the composites increased from 1.305 to $1.442 \mathrm{~g} / \mathrm{cm}^{3}$ with the increased content of hydrate zinc borate from 0 to $30 \mathrm{phr}$. Hydrated zinc borate has a higher density $\left(2.67 \mathrm{~g} / \mathrm{cm}^{3}\right)$ compared with silicone rubber $\left(1.1-1.2 \mathrm{~g} / \mathrm{cm}^{3}\right)$. The density of the composites increased due to the addition of high-density components. Meanwhile, the shore A hardness value of the SR 5 composite with $30 \mathrm{phr}$ hydrate zinc borate increased by 8 compared to the SR0 composite without hydrate zinc borate, which meant hydrate zinc borate reduced the flexibility of silicone rubber molecular chains.

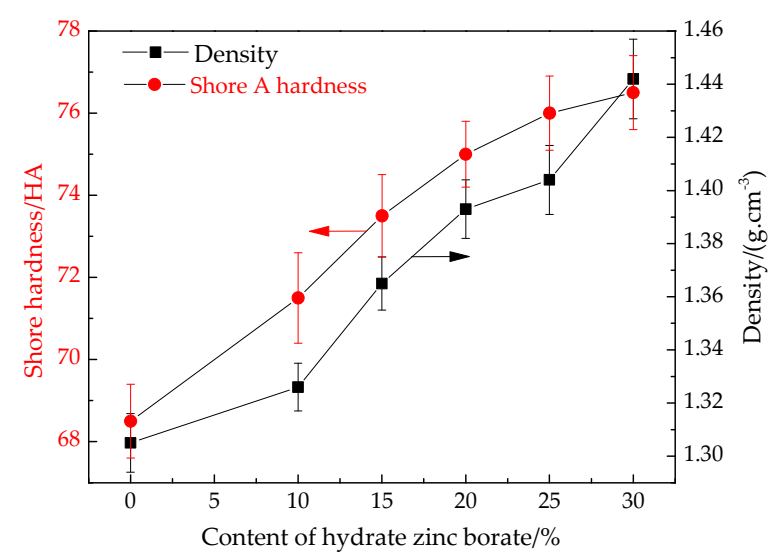

Figure 1. Density and hardness of ceramifiable silicone rubber composites with different contents of hydrated zinc borate.

\subsection{Mechanical Properties of Ceramifiable Silicone Rubber Composites}

The effect of the hydrated zinc borate content on tensile strength and elongation of the ceramifiable silicone rubber composites at break are shown in Figure 2. With the increased content of hydrate zinc borate, both the tensile strength and the elongation of the composites, to a certain extent, decreased at break. The tensile strength decreased from 6.94 to $5.32 \mathrm{MPa}$, and the elongation at break decreased 
from $531.79 \%$ to $314.34 \%$. Consequently, the content of the hydrated zinc borate had a negative effect on the tensile strength and elongation of the composites at break. Adding hydrate zinc borate to the silicone rubber harmed the continuity of the matrix and led to the formation of weak interfacial interactions, resulting in the increment of defects. On the other hand, in the process of the composites being stretched, particles hindered the elongation of silicone rubber molecular chains, decreasing the elongation at break, which also illustrated the increase of the hardness of the composites.

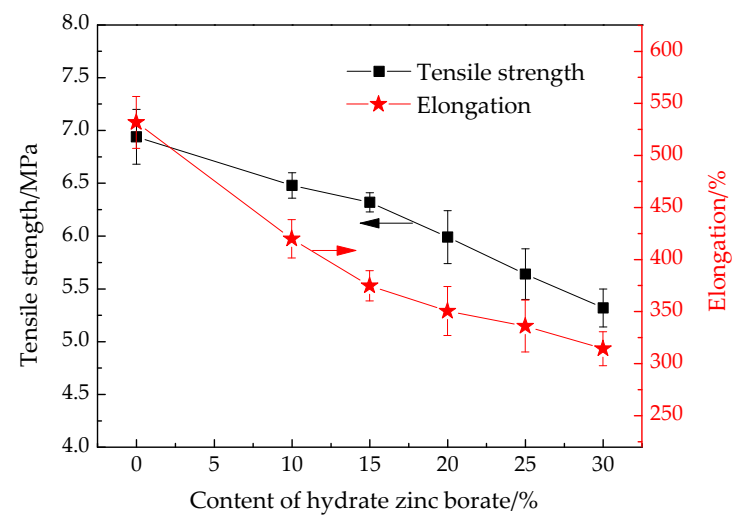

Figure 2. Tensile strength and elongation of ceramifiable silicone rubber composites, at break, with different content of hydrated zinc borate.

\subsection{Thermal Gravimetric Analysis (TGA)}

Figure 3 shows the TG and DTG curves of six different silicone rubber composite samples and hydrated zinc borate in air. $\mathrm{T}_{5}, \mathrm{~T}_{\max 1}, \mathrm{~T}_{\max 2}$, and residue weight at $1300^{\circ} \mathrm{C}$ are listed in Table 2 . It can be seen that silicone rubber composites containing hydrated zinc borate underwent two stages of thermal decomposition process in air. The first stage at $332-425^{\circ} \mathrm{C}$ was attributed to the decomposition of hydrated zinc borate, and the second stage at $425-625^{\circ} \mathrm{C}$ was due to silicone rubber, as seen in Figure $3 \mathrm{~b} . \mathrm{T}_{5}$ and $\mathrm{T}_{\max 2}$ of SR1, SR2, SR3, SR4, and SR5 were lower than those of SR0. With the increased content of hydrated zinc borate, $\mathrm{T}_{5}$ decreased from 430 to $407^{\circ} \mathrm{C}$ and $\mathrm{T}_{\max 2}$ shifted from 506.9 to $491.1^{\circ} \mathrm{C}$. Moreover, the residue weight at $1300{ }^{\circ} \mathrm{C}$ increased from $60.39 \%$ to $64.87 \%$, as seen in Figure $3 \mathrm{a}$ and Table 2. The low decomposition temperature indicated the reduction of the thermal stability of the composites under air. This was mainly attributed to hydrated zinc borate, which accelerated the thermal decomposition of silicone rubber composites. The catalytic process of silicone rubber composite, by metal ions from decomposition, has already been reported in the literature [3,21]. On the other hand, the interaction between fillers and molecule chains of silicone rubber could cause the decrease of thermal stability of the silicone rubber composites [3].
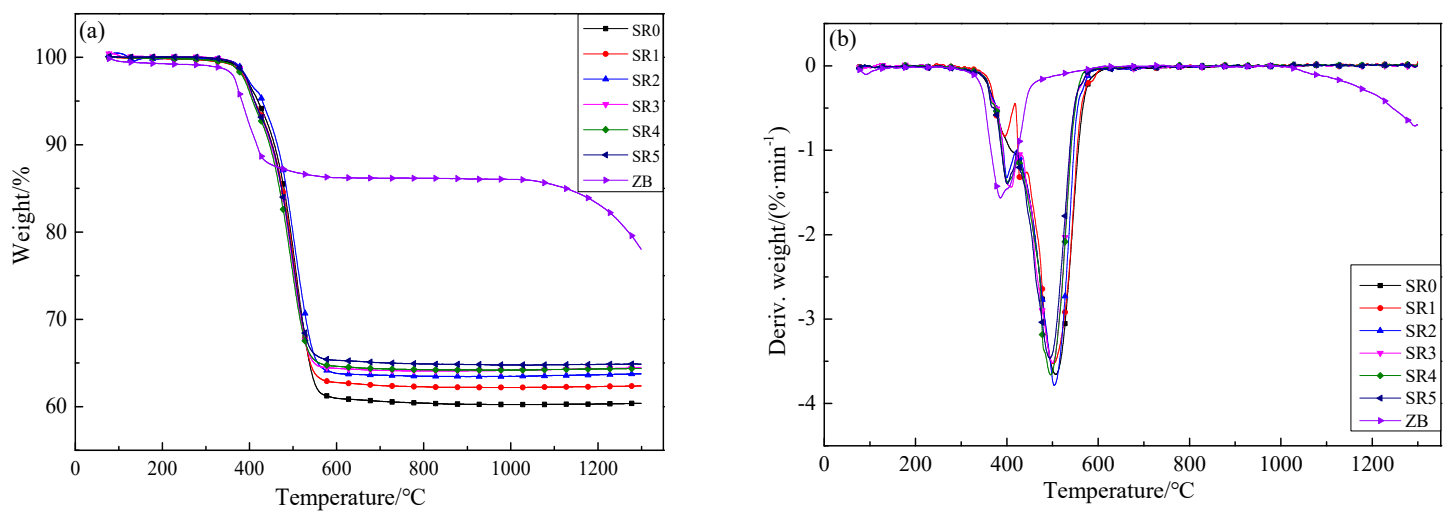

Figure 3. TG and DTG curves for ceramifiable silicone rubber composites and hydrated zinc borate: (a) TG curves and (b) DTG curves. 
Table 2. TGA parameters of the composites with different loading of hydrated zinc borate (ZB).

\begin{tabular}{ccccc}
\hline Sample Code & $\mathbf{T}_{\mathbf{5}} \mathbf{1}^{\circ} \mathbf{C}$ & $\mathbf{T}_{\mathbf{m a x}} \mathbf{1} /{ }^{\circ} \mathbf{C}$ & $\mathbf{T}_{\mathbf{m a x} \mathbf{2}}{ }^{\mathbf{}} /{ }^{\circ} \mathbf{C}$ & Residue Weight/wt $\%$ \\
\hline SR0 & 430 & $/$ & 506.9 & 60.39 \\
SR1 & 420 & 399.7 & 503.7 & 62.37 \\
SR2 & 412 & 395.8 & 501.3 & 63.77 \\
SR3 & 412 & 402.1 & 499.8 & 64.44 \\
SR4 & 412 & 400.8 & 493.8 & 64.37 \\
SR5 & 407 & 409.5 & 491.1 & 64.87 \\
ZB & 383 & 385.4 & $/$ & 78.04
\end{tabular}

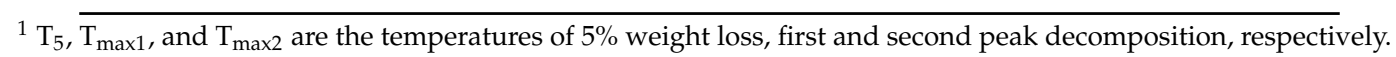

Decomposition reactions of hydrated zinc borate occurred due to heat absorption during $320-450{ }^{\circ} \mathrm{C}$, liberating water, boric acid and boron oxide, as seen in Figure $3 \mathrm{~b}$. $\mathrm{T}_{\max 1}$ was the maximum decomposition temperature of hydrated zinc borate. In this process, crystal water from the hydrated zinc borate was liberated and gasified, which caused the main mass loss of the silicone rubber composites. From Figure 3a, the value of the mass loss is about $14 \%$ for hydrated zinc borate, which is consistent with the theoretical water content of hydrated zinc borate (14.5\%). Boron oxide, one of the decomposition products, started to soften at $325^{\circ} \mathrm{C}$ and turned to liquid at $500{ }^{\circ} \mathrm{C}$ [22], which could form a perfect protective layer to cut off the pervasion of external heat and decrease mass loss, improving residue weight. With the continuous increase of temperature, the decomposition reaction would continue. The main decomposition of silicone rubber composites occurred at $425-625{ }^{\circ} \mathrm{C}$. The macromolecular chains of silicone rubber were ruptured to form cyclic oligomers, including cyclic trimers and tetramers [23]. Cyclic oligomers were decomposed and ulteriorly oxidized at high temperature in air, producing $\mathrm{CO}_{2}, \mathrm{H}_{2} \mathrm{O}(\mathrm{g})$, and $\mathrm{SiO}_{2}$, which resulted in the second main mass loss of composites.

\subsection{FTIR Analysis}

Figure 4 shows the FTIR spectra of ceramic residue obtained by the combustion of silicone rubber composite (SR5) at different temperatures. A broad peak between 3300 and $3500 \mathrm{~cm}^{-1}$ was assigned to the vibration of hydroxyl $(-\mathrm{OH})$. Hydroxyl was mainly from crystal water in the silicone rubber composite before heat treatment, and after combustion, the porous char layer tended to absorb moisture from the release of crystal water and air [24]. The FTIR peaks were assigned as follows: $2964 \mathrm{~cm}^{-1}$ for $-\mathrm{CH}_{3}$ asymmetric stretching, $1415 \mathrm{~cm}^{-1}$ for $-\mathrm{CH}_{3}$ deformation, and $1264 \mathrm{~cm}^{-1}$ for $-\mathrm{CH}_{3}$ wagging due to the vibration of methyl groups $\left(-\mathrm{CH}_{3}\right)$ and which disappeared after combustion at $500{ }^{\circ} \mathrm{C}$ and higher temperatures, which meant that oxidation or other reactions of methyl and methylene on the side chains occurred. Characteristic absorption peaks of the $\mathrm{Si}-\mathrm{C}$ bond at 815 and $800 \mathrm{~cm}^{-1}$ became weak after decompositions above $500{ }^{\circ} \mathrm{C}$, which illustrated the destruction of the network structure of silicone rubber, resulting in fracture of the Si-C bond. The peaks observed at 1099 and $467 \mathrm{~cm}^{-1}$ were associated with the stretching and deformation vibration of $\mathrm{Si}-\mathrm{O}$ bond, respectively. Hence, it inferred that the decomposition and oxidation of silicone rubber produced $\mathrm{SiO}_{2}, \mathrm{H}_{2} \mathrm{O}$, and $\mathrm{CO}_{2}$ above $400{ }^{\circ} \mathrm{C}$, according to the disappearance of methyl groups $\left(-\mathrm{CH}_{3}\right)$, the fracture of $\mathrm{Si}-\mathrm{C}$ bond, and enhancement of the $\mathrm{Si}-\mathrm{O}$ bond. The FTIR peaks marked at 1409 and $917 \mathrm{~cm}^{-1}$ were characteristic absorption peaks of the $\mathrm{B}-\mathrm{O}$ bond, which was from the decomposition reaction of zinc borate. The peak at $673 \mathrm{~cm}^{-1}$ was ascribed to the vibration of $\mathrm{Al}-\mathrm{O}-\mathrm{Si}$ groups and became strong above $800{ }^{\circ} \mathrm{C}$, which indicated that some eutectic reactions between $\mathrm{Al}_{2} \mathrm{O}_{3}$ and $\mathrm{SiO}_{2}$ happened to form aluminosilicate [19]. 


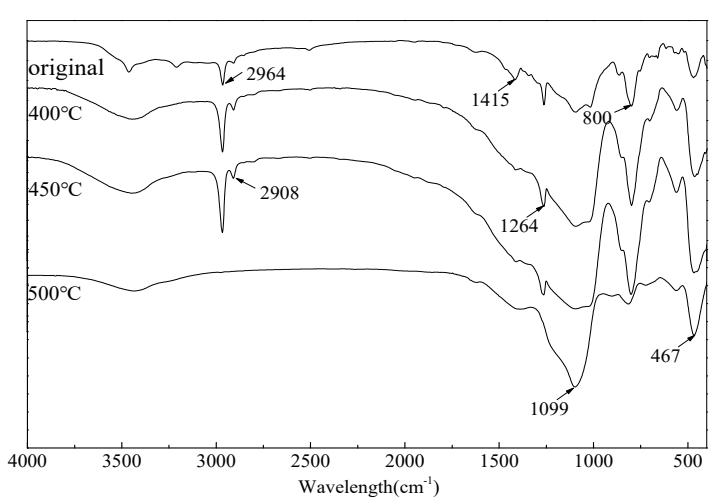

(a)

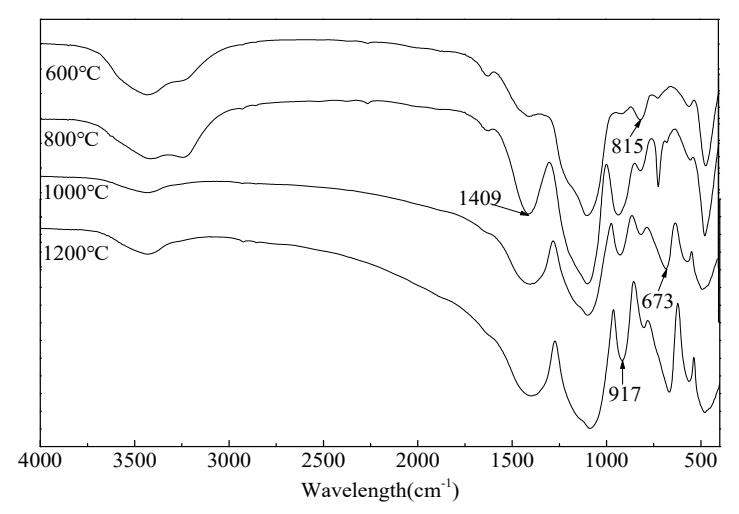

(b)

Figure 4. FTIR spectra for ceramic residue: (a) original, $400{ }^{\circ} \mathrm{C}, 450{ }^{\circ} \mathrm{C}$ and $500{ }^{\circ} \mathrm{C}$; (b) $600{ }^{\circ} \mathrm{C}, 800{ }^{\circ} \mathrm{C}$, $1000^{\circ} \mathrm{C}$ and $1200^{\circ} \mathrm{C}$.

\subsection{XRD Analysis}

The XRD patterns of ceramic residue of the sample SR5 are illustrated in Figure 5. A large hump appeared at around $2 \theta=17-25^{\circ}$ for residue calcinated at $500{ }^{\circ} \mathrm{C}$, indicating the presence of amorphous $\mathrm{SiO}_{2}$. Amorphous $\mathrm{SiO}_{2}$ was generated from the decomposition of silicone rubber and might be the original additional $\mathrm{SiO}_{2}$. The diffraction peaks at $2 \theta=16.4,26.2,30.9,33.1,35.2,40.9$, and $60.8^{\circ}$ were assigned to mullite $\left(3 \mathrm{Al}_{2} \mathrm{O}_{3} \cdot 2 \mathrm{SiO}_{2}\right)$. The diffraction peaks of zinc borate were weak and affected by mullite $\left(3 \mathrm{Al}_{2} \mathrm{O}_{3} \cdot 2 \mathrm{SiO}_{2}\right)$ and amorphous $\mathrm{SiO}_{2}$. When the combustion temperature was $600{ }^{\circ} \mathrm{C}$, the main phase in the mixture was still mullite from the XRD patterns, but the diffraction peak of zinc borate $\left(3 \mathrm{ZnO} \cdot \mathrm{B}_{2} \mathrm{O}_{3}\right)$ appeared at around $2 \theta=28^{\circ}$, which illustrated that hydrated zinc borate had dehydrated to form zinc borate $\left(2 \mathrm{ZnO} \cdot 3 \mathrm{~B}_{2} \mathrm{O}_{3}\right)$ before $600{ }^{\circ} \mathrm{C}$. Thermal decomposition of zinc borate $\left(2 \mathrm{ZnO} \cdot 3 \mathrm{~B}_{2} \mathrm{O}_{3}\right)$ produced boron oxide $\left(\mathrm{B}_{2} \mathrm{O}_{3}\right)$ and zinc borate $\left(3 \mathrm{ZnO} \cdot \mathrm{B}_{2} \mathrm{O}_{3}\right)$. With the increase of temperature, the crystal structure of zinc borate was changed from a monoclinic to cubic lattice system. From the XRD pattern, cubic zinc borate $\left(4 \mathrm{ZnO} \cdot 3 \mathrm{~B}_{2} \mathrm{O}_{3}\right)$ became the main phase at the temperature of 700 and $800{ }^{\circ} \mathrm{C}$. When the combustion temperature was $900{ }^{\circ} \mathrm{C}$, the peaks of zinc borate were weakened while the new phrase appeared, namely zinc aluminate $\left(\mathrm{ZnO} \cdot \mathrm{Al}_{2} \mathrm{O}_{3}\right)$, which suggested that an interaction between zinc borate and aluminosilicate had occurred. During the temperature rise from 1000 to $1300{ }^{\circ} \mathrm{C}$, zinc aluminate became the main phase, and some amorphous phase was also present. The diffraction peaks of aluminum-rich mullite $\left(9 \mathrm{Al}_{2} \mathrm{O}_{3} \cdot 2 \mathrm{SiO}_{2}\right)$ appeared, and the amount of amorphous phase increased. According to the XRD pattern analysis, many thermal chemical reactions occurred during the process of silicone rubber composite combustion, which was consistent with the results of the FTIR spectra. 


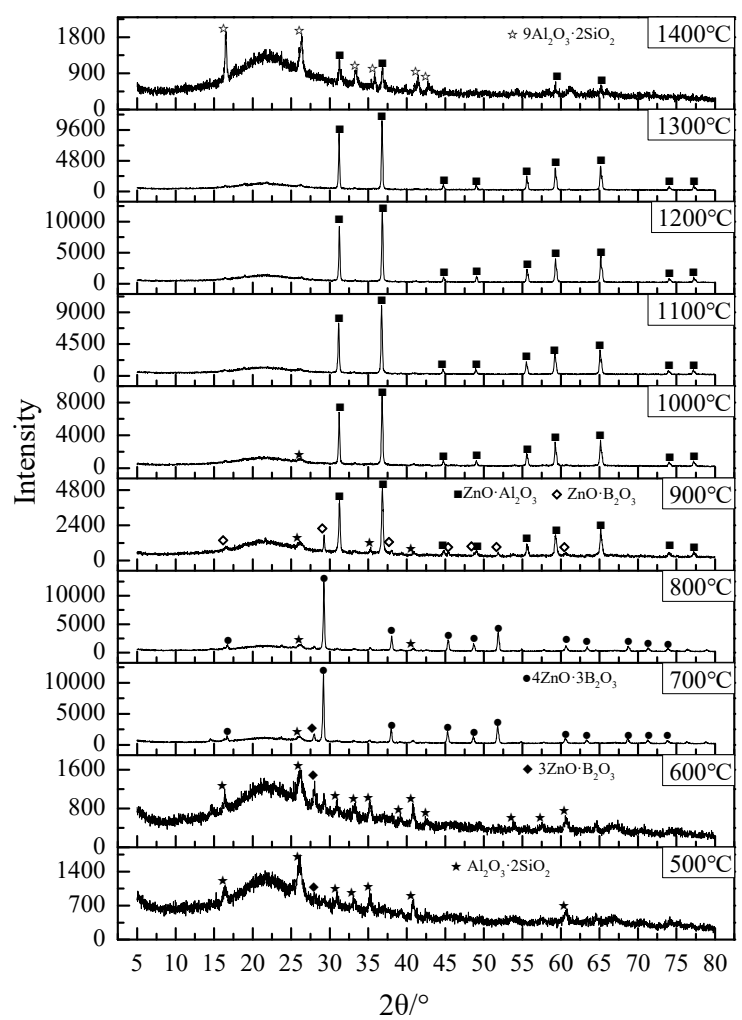

Figure 5. The XRD patterns of combustion residue at different temperatures.

\subsection{Microstructure of the Residue}

Figure 6 gives the microstructure images of interior structure of combustion residue with $30 \mathrm{phr}$ content of hydrated zinc borate at different calcined temperatures. The microscale morphology shows that filler particles were uniformly distributed in the matrix and had good compatibility with silicone rubber from the Figure 6a. After calcination at $400{ }^{\circ} \mathrm{C}$, microcracks and -pores appeared on the surface of the composites, due to release of crystalline water of the hydrated zinc borate and scission of $\mathrm{Si}-\mathrm{CH}_{3}$ of the silicone rubber, as seen in Figure $6 \mathrm{~b}$. When the combustion temperature reached $800{ }^{\circ} \mathrm{C}$, silicone rubber was decomposed and crystalline water was thoroughly released, resulting in the appearance of lots of micropores, as seen in Figure $6 c$, and some spheres and rods appeared in the residue. These spheres and rods were formed by the melting of low-melting-point substances in the system. For instance, $\mathrm{B}_{2} \mathrm{O}_{3}$, from the decomposition of hydrated zinc borate, melted at approximately $500{ }^{\circ} \mathrm{C}$ and flowed at higher temperatures. Then, after being cooled to room temperature, spheres and rods were formed. With the increase of combustion temperature, zinc borate melted, which resulted in the formation of many liquid phase substances. The size of the spheres became bigger and bigger, and some of them came into contact with each other, as shown in Figure 6d. Then, after thermal treatment at $1200{ }^{\circ} \mathrm{C}$, a large number of liquid phase substances were found to exist in ceramic residue, as seen in Figure 6e. Among these liquid phase substances, a bridged structure appeared. The original spherical structure had become an interconnected rod-like structure. As the temperature continued to rise, as seen in Figure 6f, a new crystalline phase with hexagonal columnar structure appeared in the ceramic residue, which indicated that thermal chemical reactions occurred between 1200 and $1400{ }^{\circ} \mathrm{C}$. From the XRD pattern analysis, the new crystalline phase was considered as aluminum-rich mullite $\left(9 \mathrm{Al}_{2} \mathrm{O}_{3} \cdot 2 \mathrm{SiO}_{2}\right)$. 

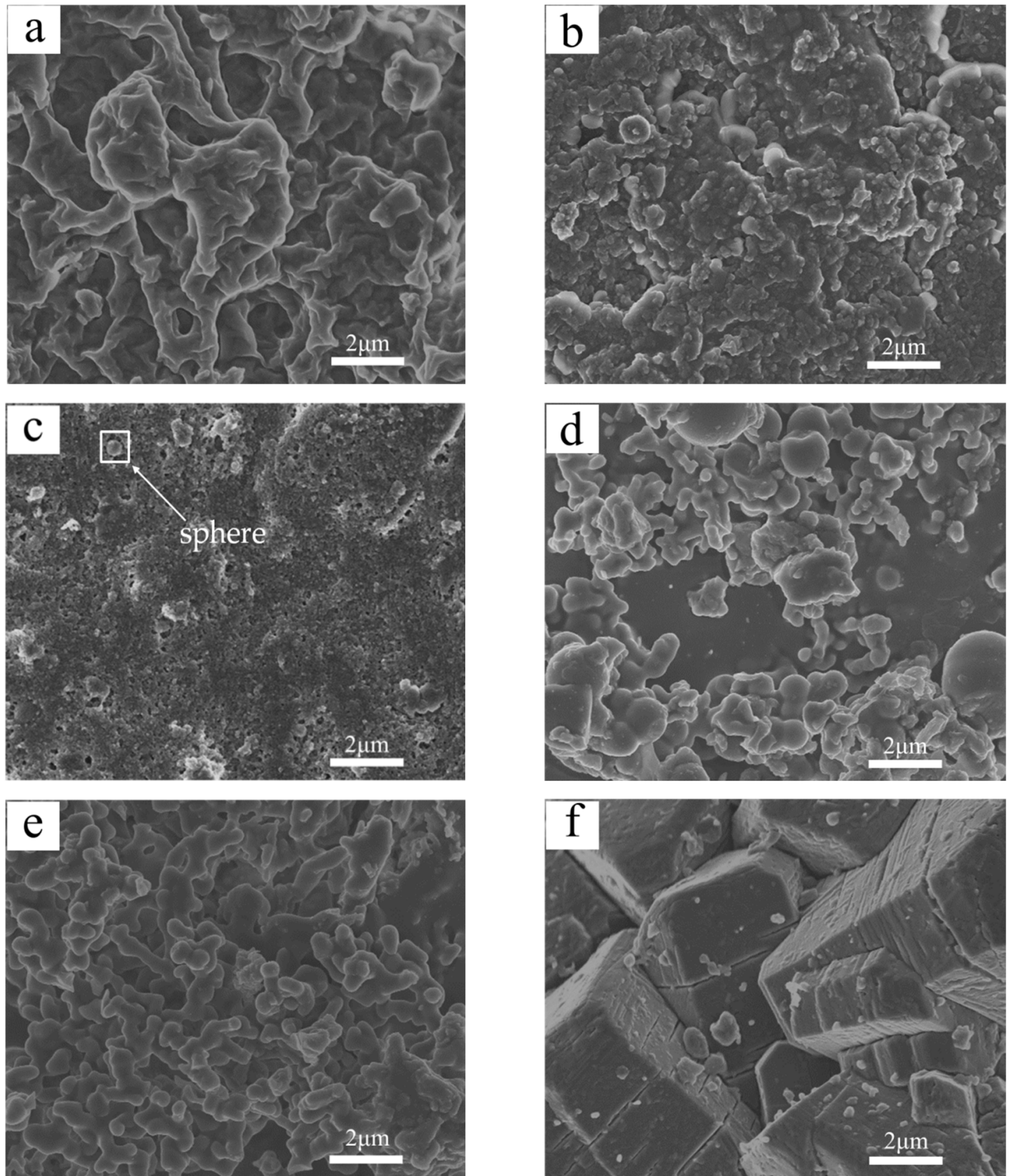

Figure 6. Micromorphology of combustion residue under different temperatures: (a) Original; (b) $400{ }^{\circ} \mathrm{C}$; (c) $800{ }^{\circ} \mathrm{C}$; (d) $1000{ }^{\circ} \mathrm{C}$; (e) $1200{ }^{\circ} \mathrm{C}$; (f) $1400{ }^{\circ} \mathrm{C}$.

\subsection{Weight Loss and Linear Shrinkage of Ceramic Residue}

The effect of the hydrated zinc borate content on the weight loss and linear shrinkage of the ceramic residue is shown in Figure 7. With the increased content of hydrated zinc borate, from 0 to $30 \mathrm{phr}$, the weight loss of the ceramic residue was reduced from $43.2 \%$ to $37.6 \%$ because the proportion of silicone rubber in the composite declined. Silicone rubber was decomposed and oxidized due to high temperatures in air, resulting in the release of a large number of gases, such as $\mathrm{CO}_{2}$ and $\mathrm{H}_{2} \mathrm{O}(\mathrm{g})$. Furthermore, with the increased loading of hydrated zinc borate, the linear shrinkage of ceramic residue increased from $15.1 \%$ to $21.9 \%$. More liquid phase was generated by the melted zinc borate during the sintering process. The liquid products flowed at high temperature and filled the microhole. Then, during cooling, the liquid products shrunk under the action of surface tension, resulting in more compact structure as shown in Figure 6e. 


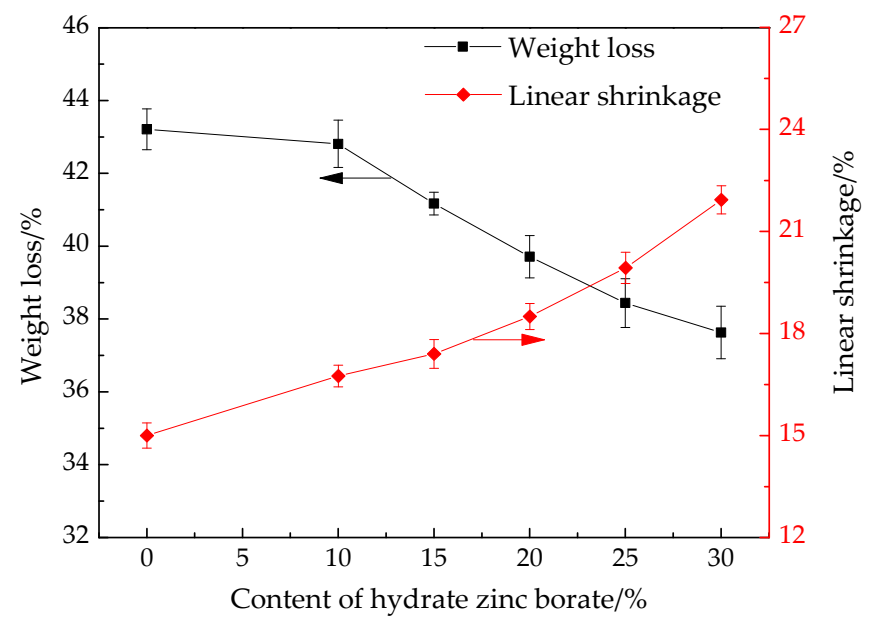

Figure 7. Weight loss and linear shrinkage of ceramic residue calcined at $1000{ }^{\circ} \mathrm{C}$ with different contents of hydrated zinc borate.

\subsection{Bending and Compressive Strength of the Residue}

Figure 8 illustrates an obvious change in the bending and compressive strength of ceramic residue obtained at $1000{ }^{\circ} \mathrm{C}$ in air. With the increased content of hydrated zinc borate, from 0 to $30 \mathrm{phr}$, the bending strength was improved from 0.11 to $11.58 \mathrm{MPa}$, and the compressive strength increased from 0.03 to $1.14 \mathrm{MPa}$. The more liquid phase produced by melted hydrated zinc borate at high temperatures was beneficial for forming the more compact structure of the ceramic residue, resulting in the higher mechanical properties of the residue. In Figure 9, the compressive strength of ceramic residue (SR5) at different temperatures in air showed similar behavior. At lower temperatures, below the softening point of hydrated zinc borate, there was little liquid phase. According to the results of microstructure test, a highly porous structure existed in the ceramic residue. The structure of the ceramic residue became compact with increasing temperature, and the compressive strength increased from 0.31 to $1.82 \mathrm{MPa}$.

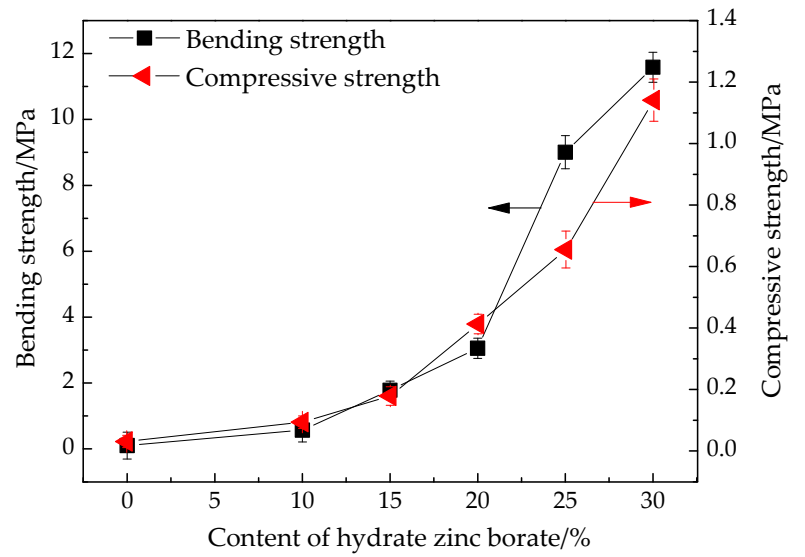

Figure 8. Bending and compressive strength of ceramic residues calcined at $1000{ }^{\circ} \mathrm{C}$ with different contents of hydrated zinc borate. 


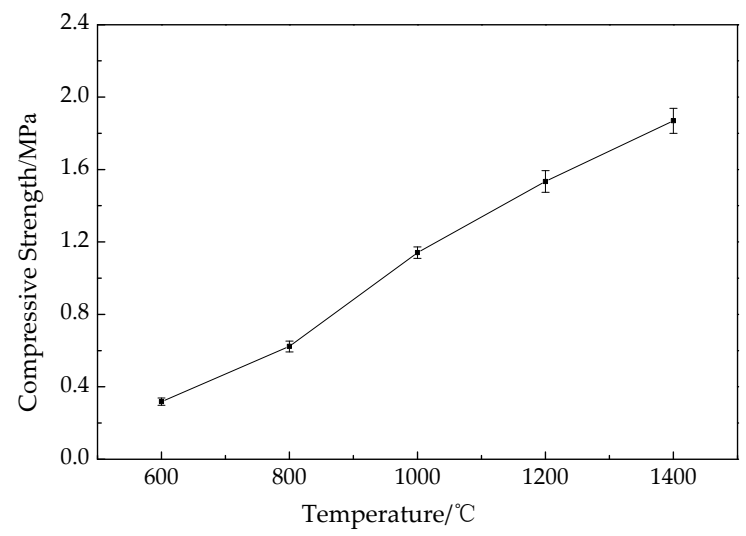

Figure 9. Compressive strength of ceramic residues calcined at different temperature.

\subsection{Ceramization Mechanism}

According to above results of data analysis, the decomposition regularity and ceramization mechanism of the ceramifiable silicone rubber composites with hydrated zinc borate are revealed. First, crystallized water of hydrated zinc borate was released and vaporized (Equation (6)), which absorbed a great quantity of the heat and diluted oxygen on the surface of the materials, retarding thermal oxidation reactions. Then, the main chain $(-\mathrm{Si}-\mathrm{O}-\mathrm{Si}-)$ of methyl vinyl silicone rubber fractured to form cyclic depolymerization (Scheme 1) [23]. Although the energy of the Si-O bond (106.1 kcal/mol) is much higher than that of $\mathrm{Si}-\mathrm{C}$ bond $(77.9 \mathrm{kcal} / \mathrm{mol})$ and $\mathrm{C}-\mathrm{C}$ bond $(82.6 \mathrm{kcal} / \mathrm{mol})$ [25], the linear molecular chain of silicone rubber has good flexibility, which impels the $3 \mathrm{~d}$ orbital electron of the $\mathrm{Si}$ to be involved in the formation of the ring-like oligomers (transition state, being oxidized to $\mathrm{SiO}_{2}$ later). Meanwhile, the side chain methyls and methylenes were oxidized to $\mathrm{CO}_{2}$ and $\mathrm{H}_{2} \mathrm{O}$, due to the presence of oxygen (Scheme 2) [26].

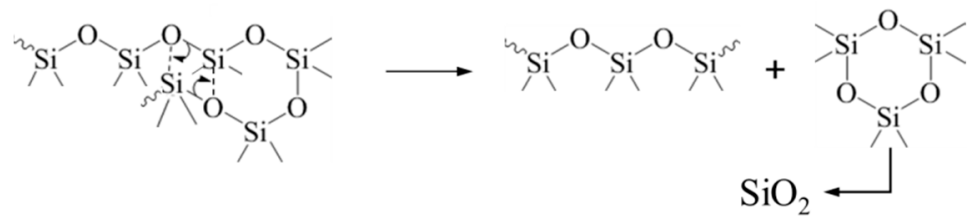

Scheme 1. Molecular chain decomposition mechanism of silicone rubber.

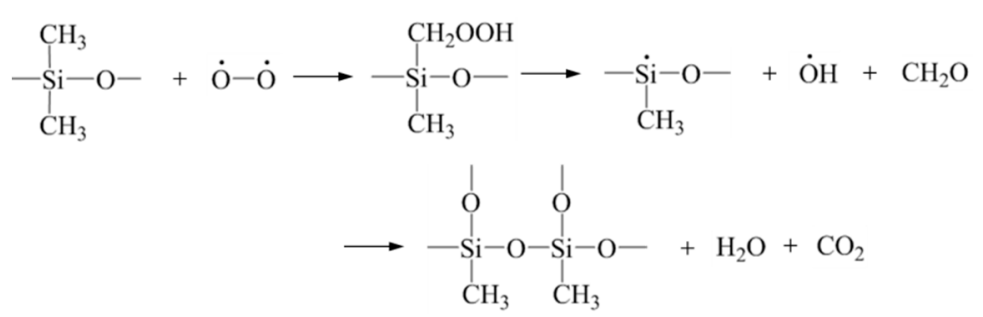

Scheme 2. Oxidation mechanism of the side chain of silicone rubber.

With the increase of temperature, kaolin $\left(\mathrm{Al}_{2} \mathrm{O}_{3} \cdot 2 \mathrm{SiO}_{2}\right)$ was decomposed to generate mullite $\left(3 \mathrm{Al}_{2} \mathrm{O}_{3} \cdot 2 \mathrm{SiO}_{2}\right.$, PDF number: 6-258) and $\mathrm{SiO}_{2}$ (Equation (7)), and zinc borate $\left(2 \mathrm{ZnO} \cdot 3 \mathrm{~B}_{2} \mathrm{O}_{3}\right)$ was decomposed to generate $4 \mathrm{ZnO} \cdot 3 \mathrm{~B}_{2} \mathrm{O}_{3}$ (cubic) and $\mathrm{B}_{2} \mathrm{O}_{3}$ (Equation (8)). $\mathrm{B}_{2} \mathrm{O}_{3}$, with low softening point, melted little by little, which caused kaolin and silica to bond together and form ceramic and a self-supporting structure with a certain mechanical strength. Eutectic reactions occurred among these oxides, producing new liquid and solid phases. At temperatures up to $900{ }^{\circ} \mathrm{C}$, new mineral phases of $\mathrm{ZnO} \cdot \mathrm{Al}_{2} \mathrm{O}_{3}$ and $\mathrm{ZnO} \cdot \mathrm{B}_{2} \mathrm{O}_{3}$ were detected in the ceramic residue, indicating the presence of thermochemical interactions between zinc borate $\left(4 \mathrm{ZnO} \cdot 3 \mathrm{~B}_{2} \mathrm{O}_{3}\right)$ and mullite 
$\left(3 \mathrm{Al}_{2} \mathrm{O}_{3} \cdot 2 \mathrm{SiO}_{2}\right)$ (Equation (9)). Finally, mullite mineral $\left(3 \mathrm{Al}_{2} \mathrm{O}_{3} \cdot 2 \mathrm{SiO}_{2}\right)$ continued to decompose and form aluminum-rich mullite (Equation (10)). With the increasing of combustion temperature and time, the new liquid phase would diffuse into the matrix, leading to bond formation among the components similar to akin to a "liquid bridge", the result of which was a ceramic protective layer with compact structure, stable shape, and adequate mechanical strength. The protective layer effectively separated external oxygen and fire from the internal material, preventing further heat dispersion and mass loss.

$$
\begin{gathered}
2 \mathrm{ZnO} \cdot 3 \mathrm{~B}_{2} \mathrm{O}_{3} \cdot 3.5 \mathrm{H}_{2} \mathrm{O} \rightarrow 2 \mathrm{ZnO} \cdot 3 \mathrm{~B}_{2} \mathrm{O}_{3}+3.5 \mathrm{H}_{2} \mathrm{O}(\mathrm{g}) \\
3\left(\mathrm{Al}_{2} \mathrm{O}_{3} \cdot 2 \mathrm{SiO}_{2}\right) \rightarrow 3 \mathrm{Al}_{2} \mathrm{O}_{3} \cdot 2 \mathrm{SiO}_{2}+5 \mathrm{SiO}_{2} \\
2\left(2 \mathrm{ZnO} \cdot 3 \mathrm{~B}_{2} \mathrm{O}_{3}\right) \rightarrow 4 \mathrm{ZnO} \cdot 3 \mathrm{~B}_{2} \mathrm{O}_{3}+3 \mathrm{~B}_{2} \mathrm{O}_{3} \\
4 \mathrm{ZnO} \cdot 3 \mathrm{~B}_{2} \mathrm{O}_{3}+3 \mathrm{Al}_{2} \mathrm{O}_{3} \cdot 2 \mathrm{SiO}_{2} \rightarrow 3\left(\mathrm{ZnO} \cdot \mathrm{Al}_{2} \mathrm{O}_{3}\right)+\mathrm{ZnO} \cdot \mathrm{B}_{2} \mathrm{O}_{3}+2 \mathrm{SiO}_{2}+2 \mathrm{~B}_{2} \mathrm{O}_{3} \\
3\left(3 \mathrm{Al}_{2} \mathrm{O}_{3} \cdot 2 \mathrm{SiO}_{2}\right) \rightarrow 9 \mathrm{Al}_{2} \mathrm{O}_{3} \cdot 2 \mathrm{SiO}_{2}+4 \mathrm{SiO}_{2}
\end{gathered}
$$

\section{Conclusions}

The effect of the hydrated zinc borate content and combustion temperature on the properties of ceramifiable silicone rubber composites was investigated. With the increased content of hydrated zinc borate from 0 to $30 \mathrm{phr}$, the density and shore A hardness increased by $10.5 \%$ and $11.7 \%$, respectively. Nevertheless, the tensile strength and elongation at break decreased by $23.3 \%$ and $40.9 \%$, respectively. In addition, the thermal decomposition and ceramifying process of the composites in a muffle furnace under air were also studied. Adding hydrated zinc borate as fluxing agent to the ceramifiable silicone rubber composites could significantly accelerate the process of thermal decomposition of the composites, decreasing the thermal stability of the composites. The $\mathrm{T}_{5}$ and $\mathrm{T}_{\max 2}$ of the ceramifiable silicone rubber composites had a certain degree of decline, while the residue weight had a significant improvement. In the process of combustion, fracture and oxidation of the molecular main chains ( $\mathrm{Si}-\mathrm{O}$ bond) and side chains ( $\mathrm{Si}-\mathrm{C}$ bond) of silicone rubber occurred, producing $\mathrm{SiO}_{2}, \mathrm{H}_{2} \mathrm{O}$, and $\mathrm{CO}_{2} . \mathrm{B}_{2} \mathrm{O}_{3}$ was generated by the thermal decomposition of zinc borate at high temperatures and participated in the formation of the residue network structure, which decreased the temperature of the ceramifying transition. New phases, zinc aluminate $\left(\mathrm{ZnO} \cdot \mathrm{Al}_{2} \mathrm{O}_{3}\right)$ and aluminum-rich mullite $\left(9 \mathrm{Al}_{2} \mathrm{O}_{3} \cdot 2 \mathrm{SiO}_{2}\right)$, appeared after high-temperature thermochemical reactions. After thermal treatment above $1000{ }^{\circ} \mathrm{C}$, a large number of liquid phase substances were found to exist in ceramic residue, and formed a bridged structure. With the increasing of temperature from 800 to $1400^{\circ} \mathrm{C}$, the network structure of the ceramic residue (SR5) became increasingly compact, and the compressive strength increased from 0.31 to $1.82 \mathrm{MPa}$, which had a better protective effect on heat transfer and mass loss. The weight loss and linear shrinkage of the ceramic residue was respectively $37.6 \%$ and $21.9 \%$, with the $30 \mathrm{phr}$ content of hydrated zinc borate. With an increased content of hydrated zinc borate, from 0 to $30 \mathrm{phr}$, the bending strength of the ceramic residue was improved from 0.11 to $11.58 \mathrm{MPa}$, and the compressive strength increased from 0.03 to $1.14 \mathrm{MPa}$.

Author Contributions: The manuscript was written through contributions of all authors. Conceptualization, Z.H.; data curation, J.S.; formal analysis, Y.Q.; methodology, J.S. and X.L.; project administration, Z.H.; supervision, Y.Q.; writing-original draft, J.S.; writing-review \& editing, J.S. and X.L. All authors have given approval to the final version of the manuscript.

Funding: This research received no external funding.

Acknowledgments: The authors thank Center for Materials Research and Analysis of Wuhan University of Technology for instrumental support. Thanks are also due to colleagues in Key Laboratory of Special Functional Materials Technology for technical support.

Conflicts of Interest: The authors declare no conflict of interest. 


\section{References}

1. George, K.; Panda, B.P.; Mohanty, S.; Nayak, S.K. Recent developments in elastomeric heat shielding materials for solid rocket motor casing application for future perspective. Polym. Adv. Technol. 2018, 29, 8-21. [CrossRef]

2. Mansouri, J.; Wood, C.A.; Roberts, K.; Cheng, Y.B.; Burford, R.P. Investigation of the ceramifying process of modified silicone-silicate compositions. J. Mater. Sci. 2007, 42, 6046-6055. [CrossRef]

3. Hamdani, S.; Longuet, C.; Perrin, D.; Lopez-Cuesta, J.M.; Ganachaud, F. Flame retardancy of silicone-based materials. Polym. Degrad. Stab. 2009, 94, 465-495. [CrossRef]

4. Genovese, A.; Shanks, R.A. Fire performance of poly(dimethyl siloxane) composites evaluated by cone calorimetry. Compos. Part A. 2008, 39, 398-405. [CrossRef]

5. Hanu, L.G.; Simon, G.P.; Mansouri, J.; Burford, R.P.; Cheng, Y.B. Development of polymer Ceramic Composites for Improved Fire Resistance. J. Mater. Pro. Tech. 2004, 153, 401-407. [CrossRef]

6. Hamdani-Devarennes, S.; Pommier, A.; Longuet, C.; Lopez-Cuesta, J.M.; Ganachaud, F. Ganachaud, Calcium and aluminium-basedfillers as flame-retardant additives in silicone matrices II. Analyses on composite residues from an industrial-based pyrolysis test. Polym. Degrad. Stab. 2011, 96, 1562-1572. [CrossRef]

7. Hamdani-Devarennes, S.; Longuet, C.; Sonnier, R.; Ganachaud, F.; LopezCuesta, J.M. Calcium and aluminum-basedfillers as flame-retardant additives in silicone matrices. III. Investigations onfire reaction. Polym. Degrad. Stab. 2013, 98, 2021-2032. [CrossRef]

8. Hanu, L.G.; Simon, G.P.; Cheng, Y.B. Thermal stability and flammability of silicone polymer composites. Polym. Degrad. Stab. 2006, 91, 1373-1379. [CrossRef]

9. Yu, L.; Zhou, S.T.; Zou, H.W.; Liang, M. Thermal stability and ablation properties study of aluminum silicate ceramic fiber and acicular wollastonite filled silicone rubber composite. J. Appl. Polym. Sci. 2014, 131, 7. [CrossRef]

10. Zhuo, D.X.; Gu, A.J.; Liang, G.Z.; Hu, J.T.; Cao, L.; Yuan, L. Flame retardancy and flame retarding mechanism of high performance hyper branched polysiloxane modified bismaleimide/cyanate ester resin. Polym. Degrad. Stab. 2011, 96, 505-514. [CrossRef]

11. Hayashida, K.; Tsuge, S.; Ohtani, H. Flame retardant mechanism of polydimethylsiloxane material containing platinum compound studied by analytical pyrolysis techniques and alkaline hydrolysis gas chromatography. Polymer 2003, 44, 5611-5616. [CrossRef]

12. Anyszka, R.; Bieliński, D.M.; Pedzich, Z.; Szumera, M. Influence of surfaces of modified montmorillonites on properties of silicone rubber-based ceramizable composites. J. Therm. Anal. Calorim. 2015, 119, 111-121. [CrossRef]

13. Hshieh, F.Y. Shielding effects of silica-ash layer on the composition of silicones and their possible applications on the fire retardancy of organic polymers. Fire. Mater. 1998, 22, 69-76. [CrossRef]

14. Zhang, G.W.; Wang, F.Z.; Huang, Z.X.; Dai, J.; Shi, M.X. Improved ablation resistance of silicone rubber composites by introducing montmorillonite and silicon carbide whisker. Materials 2016, 9, 723. [CrossRef] [PubMed]

15. Zhang, G.W.; Wang, F.Z.; Dai, J.; Huang, Z.X. Effect of functionalization of graphene nanoplatelets on the mechanical and thermal properties of silicone rubber composites. Materials 2016, 9, 92. [CrossRef]

16. Mansouri, J.; Burford, R.P.; Cheng, Y.B. Pyrolysis behaviour of silicone-based ceramifying composites. Mater. Sci. Eng. A-Struct. 2006, 425, 7-14. [CrossRef]

17. Mansouri, J.; Burford, R.P.; Cheng, Y.B.; Hanu, L. Formation of strong ceramified ash from silicone-based compositions. J. Mater. Sci. 2005, 40, 5741-5749. [CrossRef]

18. Hanu, L.G.; Simon, G.P.; Cheng, Y.B. Preferential orientation of muscovite in ceramifiable silicone composites. Mater. Sci. Eng. A-Struct. 2005, 398, 180-187. [CrossRef]

19. Guo, J.H.; Gao, W.; Wang, Y.; Liang, D.; Li, H.J.; Zhang, X. Effect of glass frit with low softening temperature on the properties, microstructure and formation mechanism of polysiloxane elastomer-based ceramizable composites. Polym. Degrad. Stab. 2017, 136, 71-79. [CrossRef]

20. Anyszka, R.; Bielinski, D.M.; Jedrzejczyk, M. Thermal behavior of silicone rubber-based ceramizable composites characterized by Fourier transform infrared (FT-IR) spectroscopy and microcalorimetry. Appl. Spectrosc. 2013, 67, 1437-1440. [CrossRef] 
21. Wang, J.H.; Ji, C.T.; Yan, Y.T.; Zhao, D.; Shi, L.Y. Mechanical and ceramifiable properties of silicone rubber filled with different inorganic fillers. Polym. Degrad. Stab. 2015, 121, 149-156. [CrossRef]

22. Laoutid, F.; Bonnaud, L.; Alexandre, M.; Lopez-Cuesta, J.M.; Dubois, P. New prospects in flame retardant polymer materials: From fundamentals to nanocomposites. Mater. Sci. Eng. R. 2009, 63, 100-125. [CrossRef]

23. Yang, D.; Zhang, W.; Yao, R.L.; Jiang, B.Z. Thermal stability enhancement mechanism of poly(dimethylsiloxane) composite by incorporating octavinyl polyhedral oligomeric silsesquioxanes. Polym. Degrad. Stab. 2013, 98, 109-114. [CrossRef]

24. Zhou, C.; Yu, L.; Luo, W.; Chen, Y.; Zou, H.W.; Liang, M. Ablation properties of aluminum silicate ceramic fibers and calcium carbonate filled silicone rubber composites. J. Appl. Polym. Sci. 2015, 132, 41619. [CrossRef]

25. Amin, M.; Akbar, M.; Amin, S. Hydrophobicity of silicone rubber used for outdoor insulation (an overview). Rev. Adv. Mater. Sci. 2007, 16, 10-26. [CrossRef]

26. Camino, G.; Lomakin, S.M.; Lageard, M. Polydimethylsiloxane thermal degradation Part 2. The degradation mechanisms. Polymer 2002, 43, 2011-2015. [CrossRef]

(C) 2019 by the authors. Licensee MDPI, Basel, Switzerland. This article is an open access article distributed under the terms and conditions of the Creative Commons Attribution (CC BY) license (http://creativecommons.org/licenses/by/4.0/). 